\title{
PENGARUH EKSTRAK BUNGA KENANGA (Canangium odoratum) DAN BUNGA KAMBOJA KUNING (Plumeria acuminata) TERHADAP MORTALITAS NYAMUK RUMAH (Culex quenquiefasciatus)
}

\author{
Ana Ulfia Hidayati1, Suhirman ${ }^{2}$, dan Dwi wahyudiati ${ }^{3}$ \\ 1Jurusan tadris IPA Biologi FITK IAIN Mataram \\ ${ }^{2}$ Dosen Jurusan Tadris IPA Biologi FITK IAIN Mataram \\ ${ }^{3}$ Dosen Jurusan Tadris IPA Biologi FITK IAIN Mataram
}

\begin{abstract}
Abstrak
Penelitian ini bertujuan untuk melihat pengaruh ekstrak bunga kenanga (Canangium odoratum) dan bunga kamboja kuning (Plumeria acuminata) terhadap mortalitas nyamuk rumah (Culex quenquiefasciatus). Penelitian ini mengunakan Rancangan Acak Lengkap (RAL) pola faktorial terdiri atas 2 faktor, yaitu faktor A (taraf $\mathrm{a}_{1}$ ekstrak bunga kenanga dan taraf $\mathrm{a}_{2}$ ekstrak bunga kamboja kuning) dan faktor B (taraf $b_{1}$ konsentrasi $20 \%$, $b_{2} 40 \%$, $\mathrm{b}_{3}$ 60\%, dan $\mathrm{b}_{4} 80 \%$ ) dengan 8 kombinasi perlakuan dan 3 ulangan. Data yang diperoleh tersebut dianalisis menggunakan ANAVA. Hasil analisis data tersebut menunjukkan bahwa F hitung $\leq$ Ftabel sehingga Ha ditolak artinya ekstrak bunga kenanga (Canangium odoratum) dan bunga kamboja kuning (Plumeria acuminata) tidak berpengaruh terhadap mortalitas nyamuk rumah (Culex quenquiefasciatus), karena sifat minyak atsiri yang mudah menguap.
\end{abstract}

Kata Kunci: Ekstrak, Bunga Kenanga (Canangium odoratum), Bunga Kamboja Kuning (Plumeria acuminata), Mortalitas. 


\section{PENDAHULUAN}

Nyamuk merupakan salah satu vector penyakit. Nyamuk membawa penyakit-penyakit berat seperti malaria, demam berdarah, dan demam penyakit kuning. Penyakit-penyakit ini menyebar dengan cepat dari satu orang ke orang lain. Nyamuk berkembang di dalam air yang tidak mengalir (air yang tidak bergerak) yang disebut air genangan. Ada beberapa cara untuk mencegah penyebaran penyakit oleh nyamuk. Salah satunya adalah menghindari resiko digigit nyamuk. Yaitu dengan menggunakan kawat jendela, ramuan anti serangga yang aman, obat nyamuk bakar, dan lain-lain. Saat ini dipasaran telah tersedia banyak obat pembasmi nyamuk, mudah didapat dan praktis untuk digunakan, tetapi kebanyakan produk tersebut berbahan kimia, oleh karena itu dilakukan penelitian tentang penolak nyamuk dengan menggunakan bahan alam.

Konsep back to nature dalam pengendalian nyamuk vector penyakit mulai banyak dilirik oleh masyarakat. Banyak informasi yang sudah menyebar luas mengenai penggunaan beberapa bahan insektisida nabati yang mampu mengusir atau menolak nyamuk yang kontak dengan manusia. Penggunaan insektisida nabati ini memiliki point penting dalam kesehatan manusia yaitu relatif aman digunakan karena tidak menyebabkan toksin atau racun pada tubuh manusia. Tanaman yang digunakan adalah bunga kenanga dan bunga kamboja kuning, digunakan tanaman bunga kenanga dan kamboja kuning karena tanaman ini mengandung minyak atsiri yang dapat berfungsi sebagai penolak nyamuk. Penelitian terdahulu juga banyak yang menyatakan bahwa kenanga dan kamboja berkhasiat dalam mengendalikan nyamuk. Oleh karena itu dapat diketahui bahwa bunga kenanga dan kamboja kuning bermanfaat sebagai pengendali nyamuk. Dalam penelitian ini bunga kenanga dan kamboja digunakan sebagai insektisida nabati untuk mengendalikan nyamuk rumah (Culex quenquiefasciatus).

Kandungan minyak atsiri yang dimiliki oleh bunga kenanga (Canangium odoratum) dan bunga kamboja kuning (Plumeria acuminata) memiliki perbedaan yaitu adanya sitronelol di dalam bunga kamboja kuning sedangkan di 
kenanga tidak ada. Kandungan-kandungan tersebut menyerang serangga dengan cara kontak langsung, racun lambung, dan racun pernafasan.

\section{METODE PENELITIAN}

Penelitian ini menggunakan jenis penelitian eksperimen dengan pendekatan kuantitatif. Rancangan penelitian ini menggunakan Rancangan Acak Lengkap (RAL) pola factorial dengan RAL yang terdiri atas 2 faktor. Faktor A dengan taraf $\mathrm{a}_{1}$ (ekstrak bunga kenanga) dan $\mathrm{a}_{2}$ (ekstrak bunga kamboja kuning), serta faktor B dengan taraf $b_{1}(20 \%), b_{2}(40 \%), b_{3}(60 \%)$, dan $b_{4}(80 \%)$ sehingga didapat $2 \times 4=8$ kombinasi perlakuan: $a_{1} b_{1}$, $a_{1} b_{2}, a_{1} b_{3}, a_{1} b_{4}, a_{2} b_{1}, a_{2} b_{2}, a_{2} b_{3}, a_{2} b_{4}$. Ulangan yang diberikan oleh peneliti, yaitu 3 sehingga perlu disediakan $3 \times 8=24$ satuan percobaan. Data yang diperoleh dari penelitian ini berupa mortalitas atau kematian yang akan dialami oleh nyamuk rumah (Culex quenquiefasciatus).

Penelitian ini dilaksanakan di Laboratorium IPA Biologi IAIN Mataram pada tanggal 13-21 Agustus 2015. Populasi dalam penelitian ini adalah seluruh nyamuk rumah (Culex quenquiefasciatus) yang ada di lingkungan Jempong Barat dan sampel yang digunakan dalam penelitian ini adalah 10 nyamuk rumah dalam setiap gelas plastik. Pada penelitian ini akan digunakan 24 buah gelas plastik (untuk perlakuan) dan 3 buah gelas plastik untuk kontrol, sehingga jumlah sampel yang digunakan adalah 270 nyamuk.

Data pada penelitian ini diperoleh dengan cara pengamatan langsung (observasi) yakni dengan cara melihat secara langsung gejala yang terjadi pada tiap perlakuan dan ulangan setelah disemprotkan ekstrak bunga kenanga dan bunga kamboja kuning kemudian menghitung jumlah nyamuk rumah yang mati pada tiap perlakuan dan ulangan sesuai dengan waktu yang telah ditentukan.

192 BIOTA: Jurnal Tadris IPA Biologi FITK IAIN Mataram 


\section{HASIL DAN PEMBAHASAN}

Data hasil penelitian untuk total tiap perlakuan dengan percobaan RAL Faktorial 2 x 4 dengan 3 ulangan dirangkum pada Tabel 4.1 Data dikumpulkan 3 hari setelah penyemprotan dari masing-masing perlakuan

\section{Tabel 1}

Data Hasil Kematian Nyamuk Rumah (Culex quenquiefasciatus)

\begin{tabular}{|c|c|c|c|c|c|c|c|c|c|}
\hline \multirow[b]{2}{*}{$\begin{array}{c}\text { Ulan } \\
\text { gan }\end{array}$} & \multicolumn{8}{|c|}{ Perlakuan } & \multirow[b]{2}{*}{$\begin{array}{l}\text { Total } \\
\text { (Y.j) }\end{array}$} \\
\hline & $\begin{array}{c}1 \\
\left(a_{1} b_{1}\right)\end{array}$ & $\begin{array}{c}2 \\
\left(a_{1} b_{2}\right)\end{array}$ & $\begin{array}{c}3 \\
\left(\mathbf{a}_{1} \mathbf{b}_{3}\right)\end{array}$ & $\begin{array}{c}4 \\
\left(a_{1} b_{4}\right)\end{array}$ & $\begin{array}{c}5 \\
\left(a_{2} b_{1}\right)\end{array}$ & $\begin{array}{c}6 \\
\left(a_{2} b_{2}\right)\end{array}$ & $\begin{array}{c}7 \\
\left(a_{2} b_{3}\right) \\
\end{array}$ & $\begin{array}{c}8 \\
\left(a_{2} b_{4}\right)\end{array}$ & \\
\hline 1 & 4 & 4 & 4 & 4 & 1 & 4 & 4 & 4 & 29 \\
\hline 2 & 4 & 3 & 3 & 4 & 4 & 4 & 4 & 4 & 30 \\
\hline 3 & 3 & 4 & 4 & 3 & 1 & 2 & 4 & 4 & 25 \\
\hline $\begin{array}{l}\text { Total } \\
\text { (Y.i) }\end{array}$ & 11 & 11 & 11 & 11 & 6 & 10 & 12 & 12 & 84 \\
\hline $\begin{array}{l}\text { Rata- } \\
\text { rata }\end{array}$ & 3.67 & 3.67 & 3.67 & 3.67 & 2 & 3.33 & 4 & 4 & 28 \\
\hline
\end{tabular}

Keterangan :

$\mathrm{a}_{1} \mathrm{~b}_{1} \quad$ : ekstrak bunga kenanga dengan konsentrasi $20 \%$

$\mathrm{a}_{1} \mathrm{~b}_{2} \quad$ : ekstrak bunga kenanga dengan konsentrasi $40 \%$

$a_{1} b_{3} \quad$ : ekstrak bunga kenanga dengan konsentrasi $60 \%$

$\mathrm{a}_{1} \mathrm{~b}_{4} \quad$ : ekstrak bunga kenanga dengan konsentrasi $80 \%$

$\mathrm{a}_{2} \mathrm{~b}_{1} \quad$ : ekstrak bunga kamboja kuning dengan konsentrasi $20 \%$

$\mathrm{a}_{2} \mathrm{~b}_{2} \quad$ : ekstrak bunga kamboja kuningdengan konsentrasi $40 \%$

$\mathrm{a}_{2} \mathrm{~b}_{3} \quad$ : ekstrak bunga kamboja kuning dengan konsentrasi $60 \%$

$\mathrm{a}_{2} \mathrm{~b}_{4} \quad$ : ekstrak bunga kamboja kuning dengan konsentrasi $80 \%$

Tabel 2

Data Hasil Sidik Ragam Nyamuk Rumah (Culex quinquiefasciatus) dengan SPSS

\begin{tabular}{|l|l|l|l|l|l|}
\hline \multicolumn{1}{|c|}{ Source } & $\begin{array}{c}\text { Type III } \\
\text { Sum of } \\
\text { Squares }\end{array}$ & df & Mean Square & \multicolumn{1}{|c|}{ F } & Sig. \\
\hline Corrected Model & $8.667^{\mathrm{a}}$ & 7 & 1.238 & 1.748 & .168 \\
\hline Intercept & 294.000 & 1 & 294.000 & 415.059 & .000 \\
\hline
\end{tabular}


ANA ULFIA HIDAYATI, DKK.

\begin{tabular}{|l|l|l|l|l|l|}
\hline Perlakuan_A & .667 & 1 & .667 & .941 & .346 \\
\hline Perlakua_B & 4.000 & 3 & 1.333 & 1.882 & .173 \\
\hline $\begin{array}{l}\text { Perlakuan_A } \\
\text { Perlakuan_B }\end{array}$ & 4.000 & 3 & 1.333 & 1.882 & .173 \\
\hline Error & 11.333 & 16 & .708 & & \\
\hline Total & 314.000 & 24 & & & \\
\hline Corrected Total & 20.000 & 23 & & & \\
\hline
\end{tabular}

\section{PEMBAHASAN}

Tumbuhan merupakan salah satu makhluk hidup yang memiliki keanekaragaman, sehingga sering digunakan atau dimanfaatkan dalam berbagai bidang seperti sandang, papan, dan pangan. Adapun tumbuhan yang dimanfaatkan dalam bidang farmakologi yaitu bunga kenanga (Canangium odoratum) dan bunga kamboja kuning (Plumeria acuminata), kedua bunga tersebut memiliki banyak manfaat karena kandungan yang terdapat di dalamnya.

Kandungan yang dimiliki oleh bunga kenanga (Canangium odoratum) dan bunga kamboja kuning (Plumeria acuminata) yaitu minyak atsiri. Tanaman kenanga (Cananga odorata) merupakan salah satu jenis tanaman penghasil minyak atsiri dan hasil studi literatur menunjukkan bahwa dalam kamboja didapatkan beberapa senyawa atsiri yang menjadi penyebab utama bunga tersebut berbauharum. Minyak atsiri merupakan salah satu hasil proses metabolisme dalam tanaman yang disintesis di dalam sel tanaman terbentuk karena reaksi antara berbagai persenyawaan kimia dengan air.

Fungsi minyak atsiri pada tanaman adalah memberi bau untuk membantu penyerbukan, media distribusi ke biji, dan penolak nyamuk. Minyak atsiri merupakan bahan aktif yang mempunyai kemampuan untuk menolak nyamuk yang mendekati manusia (mencegah terjadinya kontak langsung antara nyamuk dan manusia) sehingga manusia terhindar dari penularan penyakit akibat gigitan nyamuk.

194 BIOTA: Jurnal Tadris IPA Biologi FITK IAIN Mataram 
Kemampuan minyak atsiri menolak nyamuk disebabkan oleh beberapa senyawa seperti geraniol, linalool, eugenol, dan sitronelool. Geraniol, eugenol, dan linalool diketahui dapat meningkatkan kerja saraf sensorik dan menstimulasi saraf motorik yang menyebabkan kejang dan kelumpuhan. Sedangkan sitronelool mempunyai sifat racun (desiscant). Menurut cara kerjanya racun ini seperti racun kontak yang dapat memberikan kematian karena kehilangan cairan secara terus-menerus sehingga tubuh nyamuk kekurangan cairan.

Data hasil penelitian tentang pengaruh ekstrak bunga kenanga (Canangium odoratum) dan bunga kamboja kuning (Plumeria acuminata) terhadap mortalitas nyamuk rumah (Culex quenquiefasciatus) pada tabel 4.2. menunjukkan tidak ada pengaruh kedua ekstrak bunga terhadap mortalitas nyamuk rumah (Culex quenquiefasciatus). Hal ini dapat dilihat dari data tersebut dengan hasil $\mathrm{F}$ hitung $\leq$ Ftabel $=$ Ha ditolak.

Tidak adanya pengaruh ekstrak bunga kenanga (Canangium odoratum) dan bunga kamboja kuning (Plumeria acuminata) terhadap mortalitas nyamuk rumah (Culex quenquiefasciatus) disebabkan oleh beberapa faktor yaitu kondisi bunga yang digunakan (segar/layu), waktu pemetikan bunga, kematangan bunga dan sifat minyak atsiri.

Bunga yang masih segar memiliki kandungan minyak atsiri lebih banyak dibandingkan bunga yang layu. Karena minyak atsiri pada bunga yang layu sudah mengalami penguapan. Seperti yang dikatakan Sari Supartono dalam penelitiannya yang berjudul Ekstraksi Minyak Kenanga (Cananga odorata) untuk Pembuatan Skin Lotion Penolak Serangga. Penggunaan bunga kenanga yang masih segar dimaksudkan agar minyak atsiri yang dihasilkan menjadi lebih banyak. Penyulingan minyak atsiri menggunakan bahan kering biasanya akan menghasilkan minyak atsiri dengan jumlah yang lebih sedikit. Hal ini dikarenakan sebelum penyulingan minyak atsiri dalam tumbuhan sudah menguap terlebih dahulu akibat dari proses pengeringan. Itu juga yang dilakukan oleh Megawati dalam Penelitiannya yang berjudul Minyak Atsiri dari Kamboja Kuning, Putih, dan Merah dari 
Ekstraksi denganN-Heksana, di mana pada tahap persiapan bunga kamboja yang masih segar langsung diproses.

Selain kondisi bunga yang digunakan, waktu pemetikan bunga dan kematangan bunga yang digunakanpun memiliki pengaruh sebagaimana dinyatakan dalam penelitian Amelia (2011) bahwa waktu pemetikan bunga dan kematangan bunga dapat mempengaruhi hasil rendemen yang diperoleh.

Dalam penelitian ini bunga dipetik sehari sebelum mengekstrak sehingga bunga yang diekstrak sudah layu dan ratarata belum terlalu matang.Bunga-bunga tersebut juga sudah mengalami penguapan ketika diletakkan di dalam ruangan.Seperti diketahui bahwa minyak atsiri sangat mudah menguap pada suhu ruangan.Ini dapat dikaitkan dengan penelitian yang dilakukan oleh Shinta Prawoto, bahwa semakin tinggi tinggi konsentrasi minyak atsiri yang digunakan semakin sedikit jumlah nyamuk yang hinggap pada lengan seorang relawan (dalam penelitian). Namun setelah beberapa waktu akan semakin banyak nyamuk yang hinggap pada lengan, artinya daya repelan akan menjadi semakin rendah apabila minyak atsiri sudah semakin menguap. Jadi daya repelan sangat tergantung kepada konsentrasi dan waktu pemaparan hal ini disebabkan sifat minyak atsiri yang memang mudah menguap dan penguapan semakin besar pada suhu kamar.

Waktu nyamuk diberikan perlakuan dengan ekstrak bunga kenanga dan bunga kamboja kuning, dapat dilihat secara langsung bahwa nyamuk-nyamuk tersebut menjauhi cairan ekstrak yang disemprotkan dan rata-rata nyamuk-nyamuk tersebut mencari sumber udara yang masuk ke dalam gelas plastik.Itu menunjukkan perilaku nyamuk yang tidak tahan dengan bau ekstrak, sedangkan nyamuk yang tidak diberi perlakuan (kontrol) tetap berada di dasar gelas plastik.Adapun pengamatan yang dilakukan di dalam ruangan. Ruangan yang digunakan adalah kamar kos di Jempong Barat, ada dua ruangan yang digunakan. Nyamuk dimasukkan ke dalam masing-masing kamar sebanyak 50 ekor, kemudian di ruangan tersebut diletakkan bunga kenanga dan bunga kamboja kuning masing-masing 60 gr. Penguapan dari kedua bunga tersebut sangat cepat sehingga kamar tersebut sudah

196 BIOTA: Jurnal Tadris IPA Biologi FITK IAIN Mataram 
dipenuhi dengan keharuman bunga kenanga dan bunga kamboja kuning. Setelah satu jam nyamuk-nyamuk yang berada di ruang perlakuan terlihat berkurang dan tidak terjadi kontak langsung, sedangkan di ruang kontrol terjadi kontak langsung antara nyamuk dengan manusia atau orang yang berada di dalam ruangan tersebut.

Hal tersebut berkaitan dengan penelitian terdahulu tentang Potensi Minyak Atsiri Daun Nilam (Pogostemon cablin B.), Daun Babadotan (Ageratum conyzoides L),Bunga Kenanga (Cananga odorata Hook F \& Thoms)dan Daun Rosemarry (Rosmarinus officinalis $L$ )sebagai Repelan TerhadapNyamuk Aedes aegypti L.Berdasarkan hasil penelitian tersebut diketahui bahwa potensi repelan dari minyak atsiri dapat terlihat dari jumlah nyamuk yang hinggap pada lengan pengumpan, semakinlengan tidak dihinggapi nyamuk berarti potensi sebagai repelan semakin baik karena dapat menolak nyamuk. Pada pengamatan jam pertama, lenganlengan pengumpan yang diolesi minyak atsiri maupun yang diolesi DEET tidak ada yang dihinggapi nyamuk, sedangkan pada lengan kontrol yaitu lengan yang tidak diolesi repelan, nyamuk hinggap bahkan menggigit lengan kontrol tersebut.

\section{PENUTUP}

\section{Kesimpulan}

Berdasarkan rumusan masalah dan analisis data dalam penelitian ini dapat disimpulkan bahwa ekstrak bunga kenanga (Canangium odoratum) dan bunga kamboja kuning (Plumeria acuminata) tidak berpengaruh terhadap mortalitas nyamuk rumah (Culex quenquiefasciatus). Ini dapat dilihat dari analisis data di mana $\mathrm{F}$ Hitung $\leq \mathrm{F}$ Tabel sehingga $\mathrm{H}_{\mathrm{a}}$ ditolak.

\section{Saran}

1. Bagi mahasiswa IAIN khususnya jurusan IPA Biologi perlu adanya penelitian lebih lanjut tentang pengaruh ekstrak bunga kenanga dan bunga kamboja (dengan jenis lainnya) terhadap nyamuk pada siklus hidupnya yang lain. 
2. Perlu dilakukanpengembangan penelitian dengan mengacu pada organum nutritivum, diantaranya; akar (radix), daun (folium), dan batang (caulis).

3. Bagi masyarakat agar dapat memanfaatkan bunga kenanga dan bunga bunga kamboja atau tumbuhan lainnya sebagai insektisida nabati (alami).

\section{DAFTAR PUSTAKA}

Depkes RI. 2012. Cara Pembuatan Simplisia", dalam jurnal Potensi minyak atsiri daun nilam (Pogostemon cablin), daun babadotan (Ageratum conyzoides), bunga kenanga (Canangium odoratum) dan daun rosemary (Rosmarinus officinalis) sebagai repelan terhadap nyamuk Aedes aegepti.

Harris.2012. Tanaman Minyak Atsiri, dalam jurnal Potensi minyak atsiri daun nilam (Pogostemon cablin), daun babadotan (Ageratum conyzoides), bunga kenanga (Canangium odoratum) dan daun rosemary (Rosmarinus officinalis) sebagai repelan terhadap nyamuk Aedes aegepti.

Kusriningrum.2008. Perancangan Percobaan. Surabaya: Airlangga University Press.

Megawati dan Satrya wahyu Dwi Saputra.2012.Minyak Atsiri dari Kamboja Kuning, Putih, dan Merah dari Ekstraksi dengan NHeksana. Jurnal Bahan Alam Terbarukan. Amelia.2014.Perbandingan Minyak Atsiri Bunga Kenanga Segar dan Bunga Kenanga Layu (Cananga odorat). Jurnal MIPA (FMIPA Universitas Negeri Semarang, Indonesia).

Sari Supartono. 2014. Ekstraksi Minyak Kenanga (Cananga odorata) untuk Pembuatan Skin Lotion Penolak Serangga. Jurnal MIPA (FMIPA Universitas Negeri Semarang, Indonesia).

Shinta. 2012. Potensi Minyak Atsiri Daun NIlam (Pogostemon cablin), Daun Babadotan (Ageratum conyzoides L), Bunga Kenanga (Canangium odoratum) dan Daun Rosemarry (Rosmarinus officinalis) sebagai Repelan terhadap Nyamuk Aedes aegypti. Media Litbang Kesehatan.

Zaheer. 2012. Plumeria Rubra Linn.: An Indian Medicinal Plant dalam Jurnal Bahan Alam Terbarukan.

198 BIOTA: Jurnal Tadris IPA Biologi FITK IAIN Mataram 